\title{
Ina pit crater on the Moon: Extrusion of waning-stage lava lake magmatic foam results in extremely young crater retention ages
}

\author{
Le Qiao ${ }^{1,2}$, James Head ${ }^{2}$, Lionel Wilson ${ }^{3}$, Long Xiao ${ }^{1}$, \\ Mikhail Kreslavsky ${ }^{4}$, and Josef Dufek ${ }^{5}$
}

\author{
${ }^{1}$ State Key Laboratory of Geological Process and Mineral Resources, \\ Planetary Science Institute, School of Earth Sciences, China; \\ University of Geosciences, Wuhan 430074, China \\ ${ }^{2}$ Department of Earth, Environmental and Planetary Sciences, Brown University, \\ Providence, Rhode Island 02912, USA \\ ${ }^{3}$ Lancaster Environmental Centre, Lancaster University, \\ Lancaster LA1 4YQ, UK \\ ${ }^{4}$ Earth and Planetary Sciences, University of California Santa Cruz, \\ California 95064, USA \\ ${ }^{5}$ School of Earth and Atmospheric Sciences, Georgia Institute of Technology, \\ Atlanta, Georgia 30332, USA \\ Submitted to Geology 13 September 2016; revised 21 December 2016; \\ accepted 30 December 2016
}




\begin{abstract}
The enigmatic Ina feature on the Moon was recently interpreted to represent extrusive basaltic volcanic activity within the past 100 m.y. of lunar history, an extremely young age for volcanism on the Moon. Ina is a $2 \times 3 \mathrm{~km}$ D-shaped depression that consists of a host of unusual bleb-like mounds surrounded by a relatively optically fresh hummocky and blocky floor. Documentation of magmatic-volcanic processes from shield volcano summit pit craters in Hawai' $i$ and new insights into shield-building and dike evolution processes on the Moon provide important perspectives on the origin of Ina. We show that the size, location, morphology, topography, and optical maturity of Ina are consistent with an origin as a subsided summit pit crater lava lake on top of a broad $\sim 22-\mathrm{km}-$ diameter, 3.5 -b.y.-old shield volcano. New theoretical treatments of lunar shieldbuilding magmatic dike events predict that waning-stage summit activity was characterized by the production of magmatic foam in the dike and lake; the final stages of dike stress relaxation and closure cause the magmatic foam to extrude to the surface through cracks in the lava lake crust to produce the mounds. The high porosity of the extruded foams $(>75 \%)$ altered the nature of subsequent impact craters (the aerogel effect), causing them to be significantly smaller in diameter, which could bias the craterderived model ages. Accounting for this effect allows for significantly older model ages, to $\sim 3.5$ b.y., contemporaneous with the underlying shield volcano. Thus extremely young volcanic eruptions are not required to explain the unusual nature of Ina.
\end{abstract}

\title{
INTRODUCTION
}

The Ina feature on the Moon is located in mare deposits $\left(18.65^{\circ} \mathrm{N}, 5.30^{\circ} \mathrm{E}\right)$ interpreted to be ancient basalts; the $2 \AA \sim 3 \mathrm{~km}$, D-shaped shallow depression consists of bright and blocky floor materials and dozens of mounds with cross sections resembling convex meniscus shapes (Fig. 1). Lunar Reconnaissance Orbiter (LRO) data enable characterization of the units within and associated with this feature (e.g., Garry et al., 2012). Ina is located on a broad, 22-km-diameter dome displaying typical ancient mare basalt mineralogic characteristics similar to those of surrounding maria, with the surface muted by the development of an optically mature regolith layer (Schultz et al., 2006). The interior is defined by an inward-facing pit crater wall $\left(5^{\circ}-10^{\circ}\right)$ and a flat basal terrace with a steep $\left(10^{\circ}-30^{\circ}\right)$ inward-facing $~ 12$-m-high scarp (Fig. 2; Figs. DR1 and DR2 in the GSA Data Repository1). The floor slopes gently $\left(<2^{\circ}\right)$ toward the center, and mainly is $\sim 40-60 \mathrm{~m}$ below the rim crest. Approximately $50 \%$ of the interior floor is made of mounds (Fig. 2; Fig. DR1); the remainder is composed of two floor units: (1) a hummocky unit (44\%), composed of moderately optically immature terrain with irregular and pitted textures, and (2) an optically immature blocky unit (6\%) with 1-5 m blocks (Garry et al., 2012). The convex mounds rise to $20 \mathrm{~m}$ above the floor, and have marginal slopes in the range of $\sim 14^{\circ}-39^{\circ}$ (Braden et al., 2014) (Fig. 2; DR1-2). Approximately 80 of these mounds are arrayed across the floor of Ina; some form coalescing features. All the summits of the mounds are below the rim of Ina and are lower toward the center of Ina. The optical maturity of the mounds is between the mature mare surrounding Ina and the optically less mature hummocky and blocky floor units (Bennett et al., 2015). 
The discovery of Ina led to a wide range of hypotheses for its formation and, in particular, the origin of the mounds and unusual floor materials with very young apparent ages. Strain and El-Baz (1980) interpreted Ina as a collapsed summit caldera with the mounds formed by later individual lava extrusions. Schultz et al. (2006) focused on the unusual hummocky and/or blocky floor material and interpreted its rough texture and optical immaturity to be due to removal of fine materials by outgassing of juvenile volatiles $\left(\mathrm{CO}_{2}, \mathrm{H}_{2} \mathrm{O}\right)$ within the past $10 \mathrm{~m}$.y. Garry et al. (2012) suggested that lava flow inflation formed the mounds and that breakouts from the inflated mounds formed the surrounding hummocky units. Braden et al. (2014, p. 787) described similarities between Ina and dozens of smaller mare features, and found that Ina and two other features all had model ages younger than $100 \mathrm{Ma}$, based on impact crater size-frequency distributions; they interpreted the mounds to be formed by extrusive volcanism that occurred within the past 100 m.y., "significantly after the established cessation of lunar mare basaltic volcanism," a finding that challenges current lunar thermal evolution models. No single hypothesis yet successfully explains the regional setting of Ina and the nature and origin of the units within it. We use new LRO data, terrestrial analogs, and new models of lunar magma ascent and eruption (Wilson and Head, 2016, 2017a; Head and Wilson, 2017) to reassess the unusual morphologies and very young crater retention ages of Ina.

\section{GEOLOGIC SETTING AND TERRESTRIAL ANALOGS}

New LRO altimetry (Smith et al., 2010) and image (Robinson et al., 2010) data show unequivocally that Ina is located within the lunar maria and at the summit of a shield volcano, $\sim 22 \mathrm{~km}$ in diameter and $\sim 300 \mathrm{~m}$ high (Fig. 1), consistent with the initial interpretation by Strain and El- Baz (1980), and at the upper end of the diameter size range for more than 200 mare domes interpreted as small shield volcanoes (Head and Gifford, 1980). Small lunar shield volcanoes are interpreted to be formed by eruptions from a single dike source, and to be dominated by accumulating low-effusion-rate, cooling-limited flows (Head and Wilson, 2017). We used Lunar Reconnaissance Orbiter Camera (LROC) image data to count impact craters superposed on the flanks of the shield volcano below the Ina summit pit and obtained a model age of ca. $3.5 \mathrm{Ga}$ for the shield (Fig. DR3).

This documentation of Ina as a pit crater on the summit of a small ancient shield volcano permits a more confident assessment of specific terrestrial analogs. Pit craters are common at the summits of small terrestrial shield volcanoes in Hawai'i, Iceland, and elsewhere, and their characteristics provide insight into the physical properties of materials on the floors of pit craters. For example, the 1959 eruption at Pu'u Pua'i on Kīlauea (Hawaii) that flooded the Kīlauea Iki pit crater $(\sim 0.9$ x $1.6 \mathrm{~km})$ (Eaton et al., 1987) (Fig. DR4) provides a very well documented example of distinctive landforms and deposit substructure associated with lava lake formation and evolution. During the eruption, lava from the Pu'u Pua'i vent flooded the Kīlauea Iki crater floor, and the lava lake surface crust grew in thickness, forming a rigid and platy boundary layer; the magma continuously degassed, bubbles and foams accumulated below the lava crust, and during subsidence, the surface crust was locally deformed into pressure ridges. Final stages of drainage and cooling caused the lava lake surface to subside, leaving (1) a steep-sided solidified lava terrace around the lake margins and (2) several-meters-high hollow linear 
pressure ridges formed by tilted lava plates (Fig. DR4). Observations and drilling into the solidifying Kīlauea Iki lava lake (Richter and Moore, 1966) revealed that (1) the uppermost layer is a chilled glassy skin with abundant vesicles, in many places covering large flat blisters meters in diameter (macrovesicles); (2) crust exposed in cracks displayed as much as $40 \%$ vesicles; (3) vesicles were most concentrated in the upper 10 $\mathrm{m}(10 \%-25 \%)$ of the drill cores (Mangan and Helz, 1986); and (4) open void spaces (each 30-70 cm deep) were often encountered in the upper $3 \mathrm{~m}$ of the drill cores.

On the basis of these observations, we interpret the interior of Ina to be related to characteristic features associated with a lava lake at the summit of a lunar shield volcano formed $\sim 3.5$ b.y. ago. The basal terrace and steep inwardfacing scarp at the base of the interior walls of Ina are analogous to the chilled margin of a lava lake remaining after subsidence of its crusted surface, and the topographically low hummocky and/or blocky terrain is analogous to the subsided macrovesicular and microvesicular lava crust (Figs. 2 and 3; Figs. DR1 and DR4).

\section{LUNAR SHIELD VOLCANIC ERUPTIONS}

Volcanic eruptions on the Moon take place under conditions very different from those on Earth, including lower lunar gravitational acceleration, absence of atmospheric pressure, the likelihood that lunar eruptions are fed by large infrequent dikes sourced deep in the upper mantle, and the consequent paucity of shallow magma reservoirs (Wilson and Head, 2017a). Rather than the multiple eruptive phases typical of terrestrial shield volcanoes fed by magma from shallow reservoirs, lunar shield volcanoes are interpreted to form from single large dike emplacement events characterized by several major evolutionary stages: (1) dike penetration to the surface, (2) shield building by emplacement of cooling-limited flows, and (3) waning and cessation of the dike emplacement event through distinctive summit pit crater activity (Wilson and Head, 2016, 2017a; Head and Wilson, 2017). Despite these differences, an important similarity between lunar and terrestrial shield-building eruptions is the presence of magmatic volatiles (e.g., water) exsolved in the final stages of approach of magma to the surface (see Fig. DR6). However, very late stage volatile release in lunar magmas, inhibited by atmospheric pressure on Earth, can produce extremely vesicular foam that is stable on the time scale of an eruption, despite the lunar vacuum (Wilson and Head, 2016, 2017b). Volatile release from rising magmas is mainly pressure-dependent. Lunar mantle mafic melts commonly contain graphite, and reactions between graphite and various metal oxides produce $\mathrm{CO}$ gas pressures less than $\sim 200 \mathrm{MPa}(\sim 50 \mathrm{~km}$ depth) (Wetzel et al., 2015). In the final phase of the eruption, as the magma rise speed at depth approaches zero, no significant additional gas is released in the deep part of the dike, and the remaining gas production in the shallow dike and lava lake is predominantly through the release of water vapor. The combination of the near-zero magma rise rate, likely high bubble number density from abundant nucleation sites, and water contents typical of many lunar magmas (several hundred parts per million; Hauri et al., 2015), results in gas bubble sizes that are so small ( $\sim 20 \mu$ m radius) that surface tension forces allow them to remain stable against the internal gas pressures and thus to form a magmatic foam that can have a vesicularity as high as $\sim 95 \%$. The small bubble sizes, and consequently small bubble velocity relative to magma, hampers gas loss and bubble coalescence (Sahagian et 
al., 1989). These lunar magmatic foams can extend to several hundred meters below the surface in a lava lake and dike. Meanwhile, the vesicular lava lake crust, formed and disrupted by previous activity, is no longer disrupted and continues to solidify and thicken, inhibiting foam collapse and gas escape. The final stage of evolution occurs when dike overpressure decreases to zero and the elastic response of the crust attempts to close the dike, squeezing the magmatic foam toward the surface and deforming the growing lava lake crust. The relatively rigid lava lake crust is then cracked and magmatic foam is extruded through the cracks to form the mounds (Fig. 3). The erupted viscous foams assume mound-like shapes and develop a thin surface layer (formed from popped bubble wall fragments) that insulates the foam from further disruption. Extrusion of the foam causes central crust subsidence (Fig. 3) and local flexure of the crust in the immediate vicinity of the foam, enhancing the meniscuslike borders of the mounds and creating marginal moats and depressions. The final product of the shield-building eruption is the superposition and solidification of magmatic foam mounds on a lava lake crust characterized by abundant microvesicularity and macrovesicularity, and overlying a residual magmatic foam substrate. We suggest that these processes operated when the pit crater floor formed $\sim 3.5$ b.y. ago.

\section{IMPACT CRATERING AND REGOLITH DEVELOPMENT}

Lunar regolith development on ancient mare lava flows is predominantly a mechanical weathering process (fragmentation and/or comminution) of solid basalt lava by postemplacement meteoritic impacts, building up a fragmental layer that increases in thickness with time. Surface regoliths superposed on mare basalt flows emplaced $\sim 3.5$ b.y. ago have typical thicknesses of $\sim 4-5 \mathrm{~m}$ (Bart et al., 2011). Impact craters superposed on the magmatic foam mounds, however, would have an entirely different effect from those on solid basalt. Extensive laboratory experiments (e.g., Schultz et al., 2002) and numerical modeling (e.g., Wünnemann et al., 2006) have shown the significant effect of target porosity on the impact cratering processes. Differences between impacts into highly porous materials and those on typical nonporous basaltic rocks and regolith (Fig. DR5) include permanent crushing and compaction of the target material, smaller crater diameter, and much smaller amounts of ejected materials. Thus, the successive accumulation of craters on the magmatic foam mounds would result in a population of relatively smaller craters, a reduced lateral transport of regolith, and a finer grain size of ejecta compared with impacts in solid basalt and regolith targets. Impact craters superposed on the lava lake crust would also differ significantly from those on lava flow surfaces and the mounds. The lava lake crust substrate consists of a highly porous medium, the macrovesicular and microvesicular meters-thick fractured layer overlying the solidified foam from the lava lake below (Fig. 3). Impacts into this medium, in addition to crushing and fragmentation, would cause infiltration of the finer components of the regolith into the abundant voids in the substrate. Such constant infiltration would preferentially expose larger blocks and boulders, and inhibit the optical maturation of the substrate. This process is assisted by seismic sieving: the impacts cause seismic shaking, which enhances the sieving and infiltration of finer components of the regolith into the void space below. Any craters that form inside Ina in the 5-30 m range (typical for maria regolith buildup) will cause significant seismic effects (accelerations $>\sim 10 \mathrm{~m} \mathrm{~s}-2,6$ times lunar gravity, and equivalent to an intensity VIII Mercalli scale earthquake; i.e., severe 
shaking) over an area 5 times that of the crater interior (Yasui et al., 2015). Thus, the continuous formation of regolith-forming craters inside Ina, as well as larger craters outside Ina, provides a ready mechanism for continuous seismic sieving of regolith fines into subsurface void space. Together, the presence of void space and the seismic sieving process combine to inhibit the vertical accumulation of the regolith layer, to cause craters to be poorly formed and difficult to recognize, and to explain both the observed relative optical immaturity and the presence of blocks.

\section{AGE OF INA MOUNDS}

Braden et al. (2014) interpreted the Ina mounds to have formed by extrusive volcanism that occurred <100 m.y. ago, on the basis of superposed impact crater size-frequency distribution (CSFD). In order to investigate the CSFD discrepancy between the Ina shield age (ca. 3.5 Ga; Fig. DR3) and the mounds (Braden et al., 2014), we addressed the question of whether the magmatic foam substrate could be responsible for altering the superposed CSFD compared to what would be expected in normal basalt lava flows (as observed on the Ina shield volcano flanks; ca. $3.5 \mathrm{Ga}$ ). Experimental impacts showed that cratering efficiency (excavated mass/projectile mass) on highly porous targets can be readily reduced two orders of magnitude compared with cratering on low-porosity materials (Schultz et al., 2002). On the basis of these data, assuming a porosity of $75 \%$ for the extruded magmatic foam of the Ina mounds, and considering the effect of porosity on the target density, the predicted hundredfold decrease in cratering efficiency would result in a factor of three smaller crater diameter. To explore this porosity effect on the CSFD disparity between the Ina mounds and the surrounding shield areas, we scaled all of the craters identified on the shield with a factor of three diameter decrease (Fig. DR5); this yields a model age younger than $100 \mathrm{Ma}$ (85.2 Ma). This predicted factor suggests an equilibrium population at diameter $\leq 12 \mathrm{~m}$ for the Ina mound CSFD, which is comparable to that of Tycho ejecta (85 Ma model age and equilibrium at $\mathrm{D} \leq 12 \mathrm{~m}$; Hiesinger et al., 2012). On the basis of this analysis, we conclude that the discrepancy in the CSFD data between the younger than $100 \mathrm{Ma}$ age obtained by Braden et al. (2014) for the mounds, and the ca. $3.5 \mathrm{Ga}$ age obtained here for the shield flanks, can be readily explained by the response of the magmatic foam substrate to the formation and retention of superposed craters. This interpretation is supported by data from the LRO Diviner radiometer; Ina regolith, while thin, is too thick $(>10 \mathrm{~cm})$ to be <100 m.y. old (Elder et al., 2016). These late-stage pit crater evolution processes can also account for the crisp appearance of the Ina geomorphology. Typical regolith diffusive landscape evolution models (e.g., Fassett and Thomson, 2015) apply to standard regolith development on mare basalt material. They are based on the assumptions that impact cratering is the dominant process, that topography evolution can be treated as a continuum, that the net effect is diffusional, and that progressive degradation of impact craters by sandblasting will modify much larger features, topographically muting them over time. In contrast, we suggest that Ina floor units will behave very differently; units with extreme macrovesicularity (the floor) are dominated by seismic sieving and vertical regolith infiltration, and the magmatic foam mounds are dominated by superposed craters that do not tend to spread ejecta laterally. We interpret the crisp boundaries and immature terrain to represent the active processes associated with the ongoing vertical infiltration of regolith at the margins of the mounds and in the floor units, in contrast to the typical diffusive process-dominated lunar surface. 


\section{CONCLUSIONS}

Documentation of magmatic-volcanic processes from a summit pit crater on a shield volcano in Hawai'i, and shield building and dike evolution processes on the Moon, provide important perspectives on the origin of Ina and its apparently very recent age. We show that the size, location, morphology, topography, and optical maturity characteristics of Ina are consistent with an origin as a summit pit crater lava lake on top of an $\sim 22-\mathrm{km}-$ diameter shield volcano formed $\sim 3.5$ b.y. ago. Waning-stage summit activity during the formation of the shield was characterized by abundant volatile production to form stable magmatic foams in the dike and lake. The final stages of dike stress relaxation and closure caused the magmatic foam to extrude to the surface through cracks in the lava lake crust to produce mounds. The physical properties of both the pit-crater mounds and floor hummocky materials exert an influence on the nature of the regolith substrate and impact crater formation and retention processes, resulting in an anomalously young crater retention age for the Ina summit pit crater mounds, and the maintenance of a fresh, crisp appearance of the landscape. Accounting for the effects of the reduced diameter of craters formed in magmatic foam results in a shift of the estimation of the model crater retention age from $<100$ m.y. to $\sim 3.5$ b.y., contemporaneous with the underlying shield volcano, making an anomalously young formation age for Ina unnecessary. The two other similar features dated as younger than $100 \mathrm{Ma}$ (Braden et al., 2014) are also located on top of dikes (Cauchy 5, volcanic shield, ca. $58 \mathrm{Ma}$; Sosigenes, linear graben and/or collapse crater, ca. $18 \mathrm{Ma}$ ), and we reinterpret these to have similar ancient origins. The irregular mare patches documented in the maria (Braden et al., 2014) are interpreted by us to be the result of similar ancient late-stage dike closure activity, unconfined by summit pit or collapse craters.

\section{ACKNOWLEDGMENTS}

We acknowledge financial support from the NASA Lunar Reconnaissance Orbiter Lunar Orbiter Laser Altimeter (LOLA) experiment (grants NNX09AM54G and NNX11AK29G to Head) and the NASA Solar System Exploration Research Virtual Institute (SSERVI) grant for Evolution and Environment of Exploration Destinations under cooperative Agreement No. NNA14AB01A at Brown University. We also acknowledge support from the National Natural Science Foundation of China (No. 41373066) and the State Scholarship Fund (No. 201406410040), both to Qiao. 


\section{REFERENCES}

Bart, G.D., Nickerson, R.D., Lawder, M.T., and Melosh, H.J., 2011, Global survey of lunar regolith depths from LROC images: Icarus, v. 215, p. 485-490, doi:

10.1016/j.icarus.2011.07.017.

Bennett, K.A., Horgan, B.H.N., Bell, J.F., III, Meyer, H.M., and Robinson, M.S., 2015, Moon Mineralogy Mapper investigation of the Ina Irregular Mare Patch: 46th Lunar and Planetary Science Conference, abs. 2646.

Braden, S.E., Stopar, J.D., Robinson, M.S., Lawrence, S.J., van der Bogert, C.H., and Hiesinger, H., 2014, Evidence for basaltic volcanism on the Moon within the past 100 million years: Nature Geoscience, v. 7, p. 787-791, doi: 10.1038/ngeo2252.

Eaton, J.P., Richter, D.H., and Krivoy, H.L., 1987, Cycling of magma between the summit reservoir and Kīlauea Iki lava lake during the 1959 eruption of Kīlauea Volcano, in Decker, R.W., et al., eds., Volcanism in Hawai'i: U.S. Geological Survey Professional Paper 1350, p. 1307-1335.

Elder, C.M., Hayne, P.O., Ghent, R.R., Bandfield, J.L., Williams, J.P., and Paige, D.A., 2016, Regolith formation on young lunar volcanic features: 47th Lunar and Planetary Science Conference, abs. 2785.

Fassett, C.I., and Thomson, B.J., 2015, A landscape evolution perspective on how young is young on the lunar surface: 46th Lunar and Planetary Science Conference, abs. 1120.

Garry, W., Robinson, M., Zimbelman, J., Bleacher, J., Hawke, B., Crumpler, L., Braden, S., and Sato, H., 2012, The origin of Ina: Evidence for inflated lava flows on the Moon: Journal of Geophysical Research, v. 117, E00H31, doi: 10.1029/2011JE003981.

Hauri, E.H., Saal, A.E., Rutherford, M.J., and Van Orman, J.A., 2015, Water in the Moon's interior: Truth and consequences: Earth and Planetary Science Letters, v. 409, p. 252-264, doi: 10.1016/j.epsl.2014.10.053.

Head, J.W., and Gifford, A., 1980, Lunar mare domes: Classification and modes of origin: The Moon and the Planets, v. 22, p. 235-258, doi: 10.1007/BF00898434.

Head, J.W., and Wilson, L., 2017, Generation, ascent and eruption of magma on the Moon: New insights into source depths, magma supply, intrusions and effusive/explosive eruptions (Part 2: Predicted emplacement processes and observations): Icarus, v. 283, p. 176-223, doi: 10.1016 /j .icarus .2016 .05.031.

Hiesinger, H., Bogert, C., Pasckert, J., Funcke, L., Giacomini, L., Ostrach, L., and Robinson, M., 2012, How old are young lunar craters?: Journal of Geophysical Research, v. 117, E00H10, doi: 10.1029/2011JE003935.

Mangan, M.T., and Helz, R.T., 1986, The distribution of vesicles and olivine phenocrysts in samples from drill hole KI 79-3, Kīlauea Iki lava lake, Hawai'i: U.S. Geological Survey Open-File Report 86-424, 43 p.

Richter, D.H., and Moore, J.G., 1966, Petrology of the Kīlauea Iki lava lake, Hawai'i: U.S. Geological Survey Professional Paper 537-B, p. B1-B26.

Robinson, M.S., et al., 2010, Lunar Reconnaissance Orbiter Camera (LROC) instrument overview: Space Science Reviews, v. 150, p. 81-124, doi: 10.1007/s11214-010-96342. 
Sahagian, D.L., Anderson, A.T., and Ward, B., 1989, Bubble coalescence in basalt flows: Comparison of a numerical model with natural examples: Bulletin of Volcanology, $\mathrm{v}$. 52, p. 49-56, doi: 10 .1007 /BF00641386.

Schultz, P.H., Anderson, J.L.B., and Heineck, J.T., 2002, Impact crater size and evolution: Expectations for Deep Impact: 33rd Lunar and Planetary Science Conference, abs. 1875.

Schultz, P.H., Staid, M.I., and Pieters, C.M., 2006, Lunar activity from recent gas release: Nature, v. 444, p. 184-186, doi: 10.1038 /nature05303.

Smith, D., et al., 2010, The Lunar Orbiter Laser Altimeter investigation on the Lunar Reconnaissance Orbiter Mission: Space Science Reviews, v. 150, p. 209-241, doi: 10.1007/s11214-009-9512-y.

Strain, P., and El-Baz, F., 1980, The geology and morphology of Ina, in Proceedings, 11th Lunar and Planetary Science Conference: Houston, Texas, Lunar and Planetary Institute, p. 2437-2446.

Wetzel, D.T., Hauri, E.H., Saal, A.E., and Rutherford, M.J., 2015, Carbon content and degassing history of the lunar volcanic glasses: Nature Geoscience, v. 8, p. 755-758, doi: 10.1038 /ngeo2511.

Wilson, L., and Head, J.W., 2016, Three-stage eruption in lunar shield volcanos and the productions of magmatic foam: Moscow, Space Research Institute, 7th Moscow Solar System Symposium, 7MS3-MN-08.

Wilson, L., and Head, J.W., 2017b, Eruption of magmatic foams on the Moon: Formation in the waning stages of dike emplacement events as an explanation of "irregular mare patches": Journal of Volcanology and Geothermal Research , doi: 10.1016 /j .jvolgeores .2017.02.009.

Wilson, L., and Head, J.W., 2017a, Generation, ascent and eruption of magma on the Moon: New insights into source depths, magma supply, intrusions and effusive/explosive eruptions (Part 1: Theory): Icarus, v. 283, p. 146-175, doi: 10 $.1016 / \mathrm{j}$.icarus .2015.12.039.

Wünnemann, K., Collins, G.S., and Melosh, H.J., 2006, A strain-based porosity model for use in hydrocode simulations of impacts and implications for transient crater growth in porous targets: Icarus, v. 180, p. 514-527, doi: 10 .1016/j .icarus.2005 .10 .013 .

Yasui, M., Matsumoto, E., and Arakawa, M., 2015, Experimental study on impactinduced seismic wave propagation through granular materials: Icarus, v. 260, p. 320331, doi: 10 .1016 /j .icarus .2015.07 .032 (erratum available at http: / /dx .doi .org $/ 10.1016 / \mathrm{j}$. icarus .2016.02 .020). 

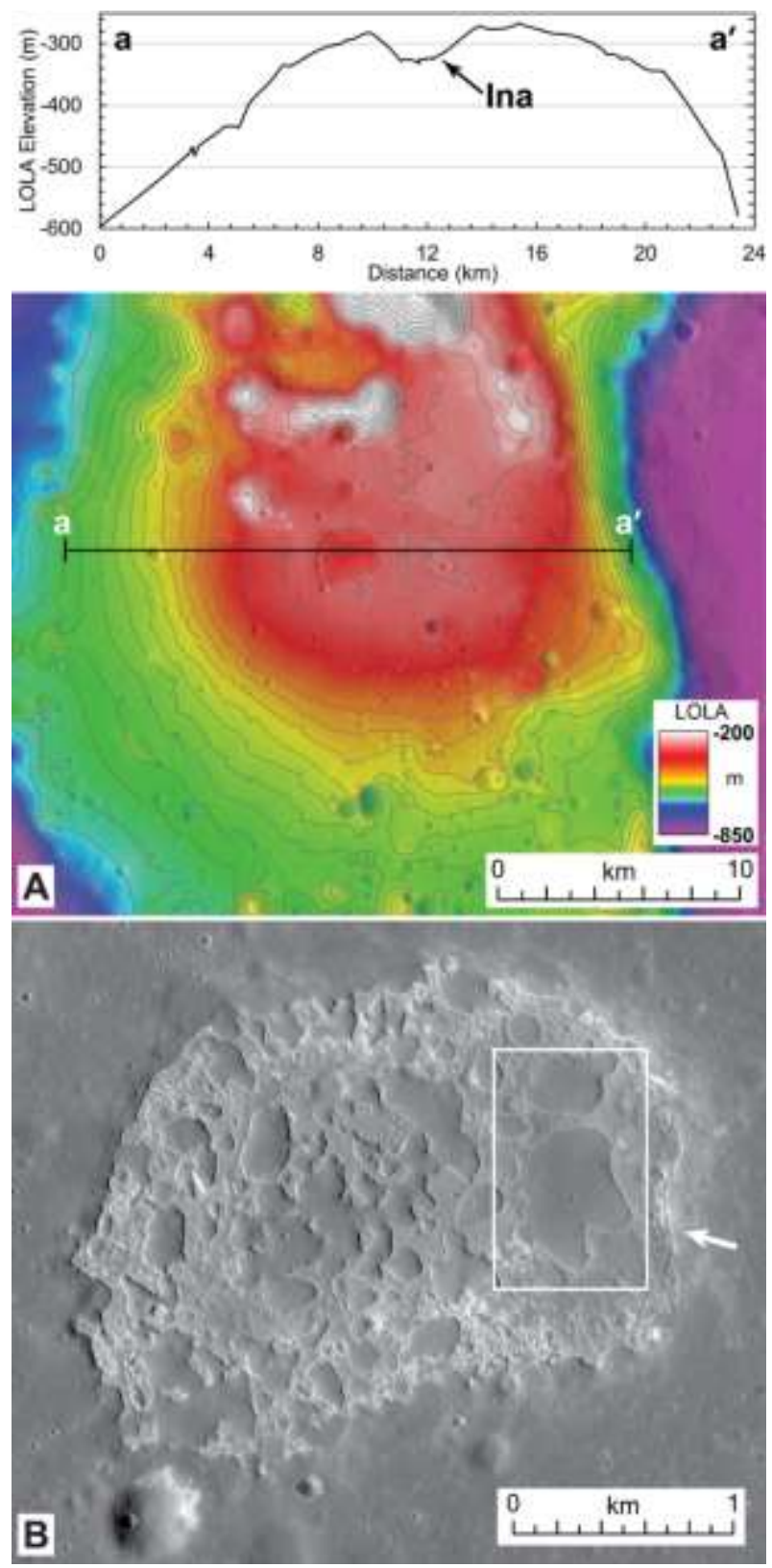

Figure 1. A: Ina shield volcano on the Moon; Lunar Orbiter Laser Altimeter (LOLA) topography overlying Kaguya Terrain Camera mosaic TCO_MAPe04_N21E003N18E006SC, 25 m contour interval. Top: West-east elevation

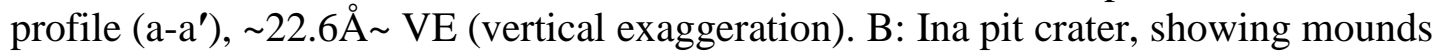
(gray) and hummocky and/or blocky floor units; Lunar Reconnaissance Orbiter Camera Narrow Angle Camera M119815703, 0.48 m/pixel, 56 ̊̊a incidence angle. White rectangle marks location of Figure 2B; white arrow shows viewing direction of Figure $2 \mathrm{~A}$. 


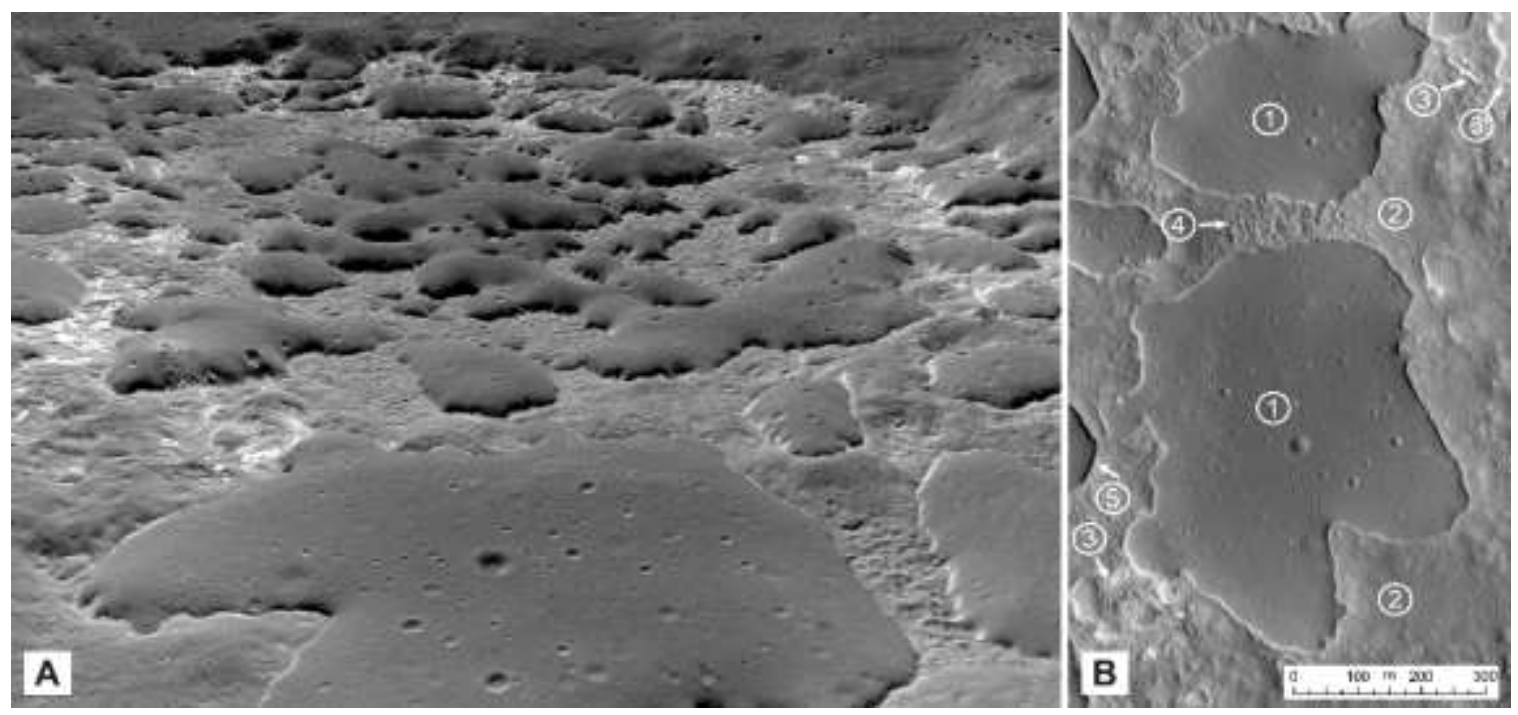

Figure 2. A: Perspective view of Ina interior (on the Moon); Lunar Reconnaissance Orbiter Camera (LROC) Narrow Angle Camera (NAC) M119815703 overlaid on LROC NAC digital terrain model; view from east to west across Ina. Vertical exaggeration is $\sim 3$. B: Morphological characteristics of the Ina interior. Relatively flat basal terraces (6) at the edge of the Ina interior. The irregularly shaped mounds (1) are surrounded by floor terrain with hummocky (2) and pitted (4) textures, and blocky materials (3).

Topographically lower moats (5) are often present at the margin of the mounds. Portion of LROC NAC M119815703.

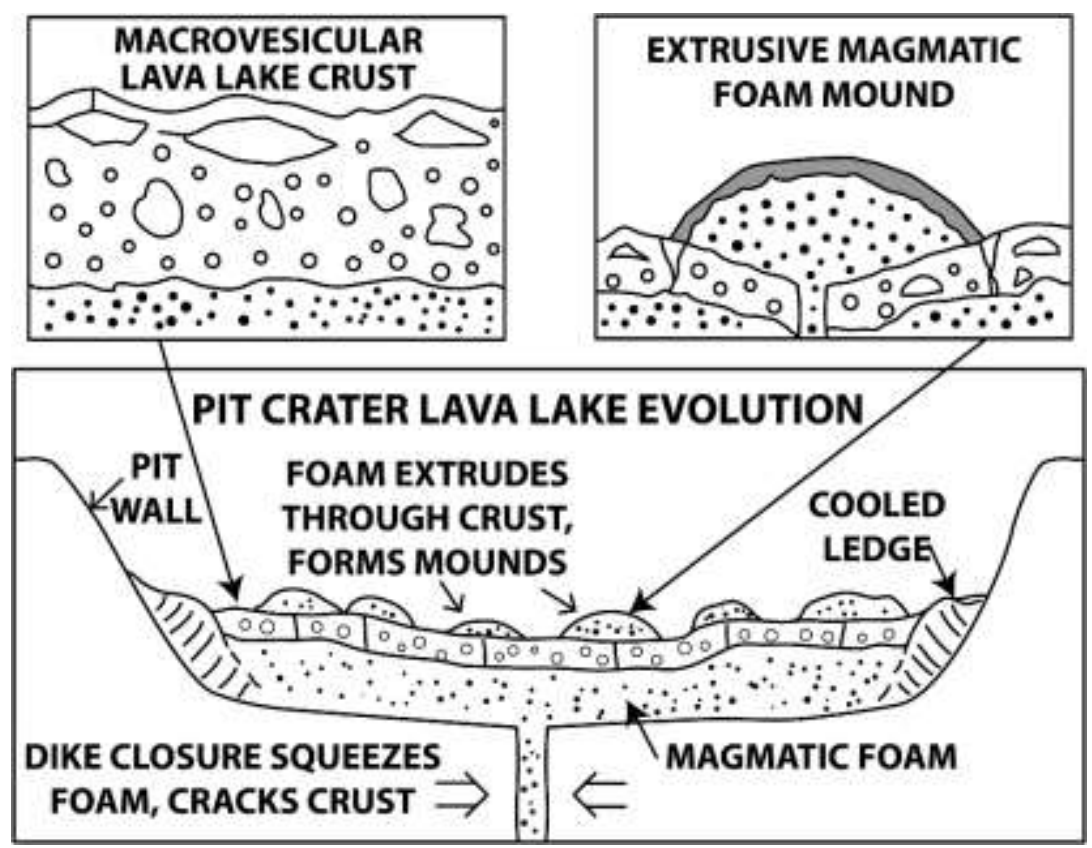

Figure 3. Cross section of the waning stage process of magmatic foam emplacement in the Ina summit pit crater (Moon). 
GSA Data Repository item 2017135 | doi:10.1130/G38594.1

Ina Pit Crater on the Moon: Extrusion of waning-stage lava lake magmatic foam results in extremely young crater retention ages. Qiao et al., 2017.
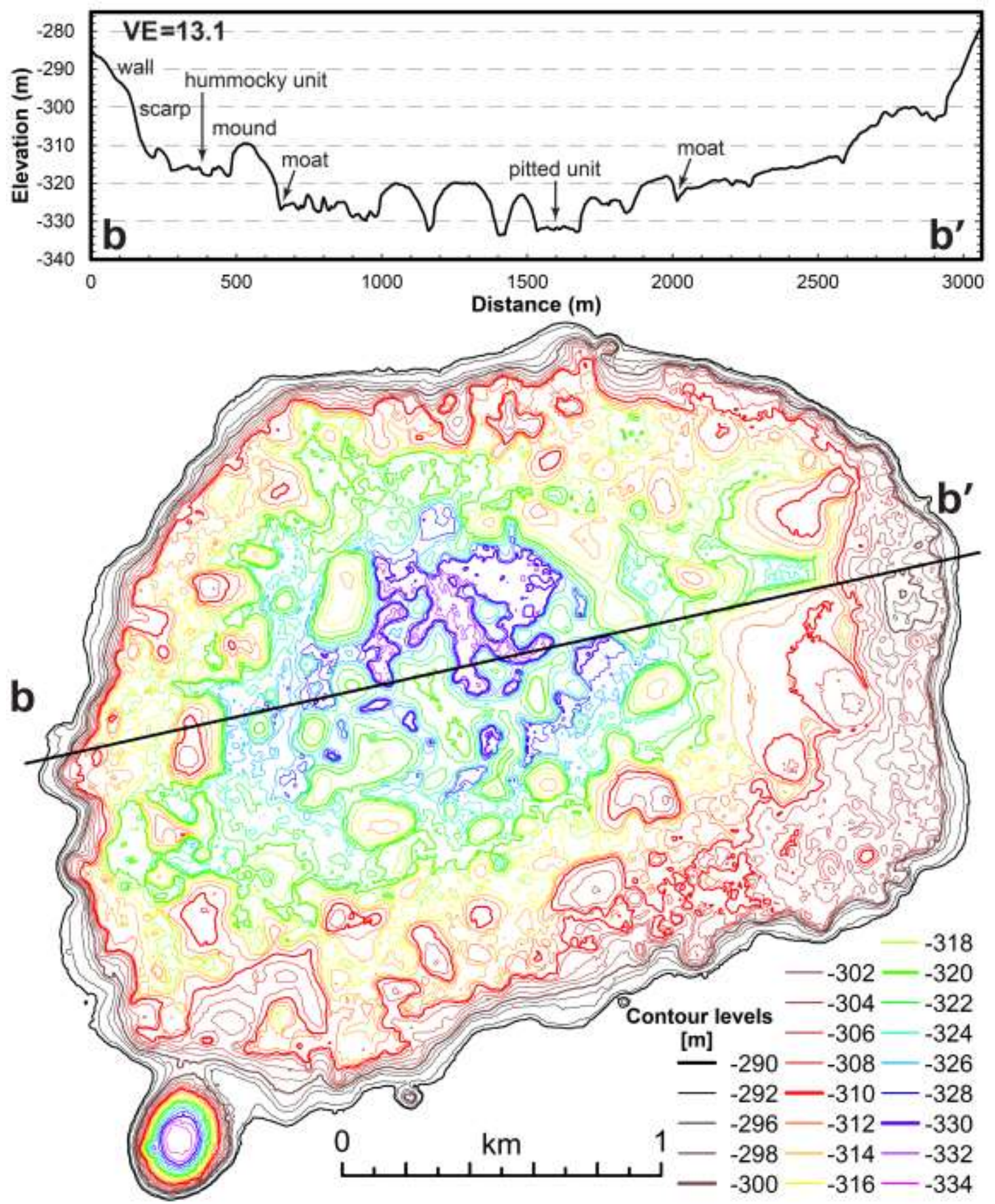
Fig. DR1. Contour map of Ina interior, derived from LROC NAC DTM. Contour interval $2 \mathrm{~m}$, bold contour every $10 \mathrm{~m}$. A W-E NAC DTM-derived elevation profile (b$\left.b^{\prime}\right)$ is plotted at the top.

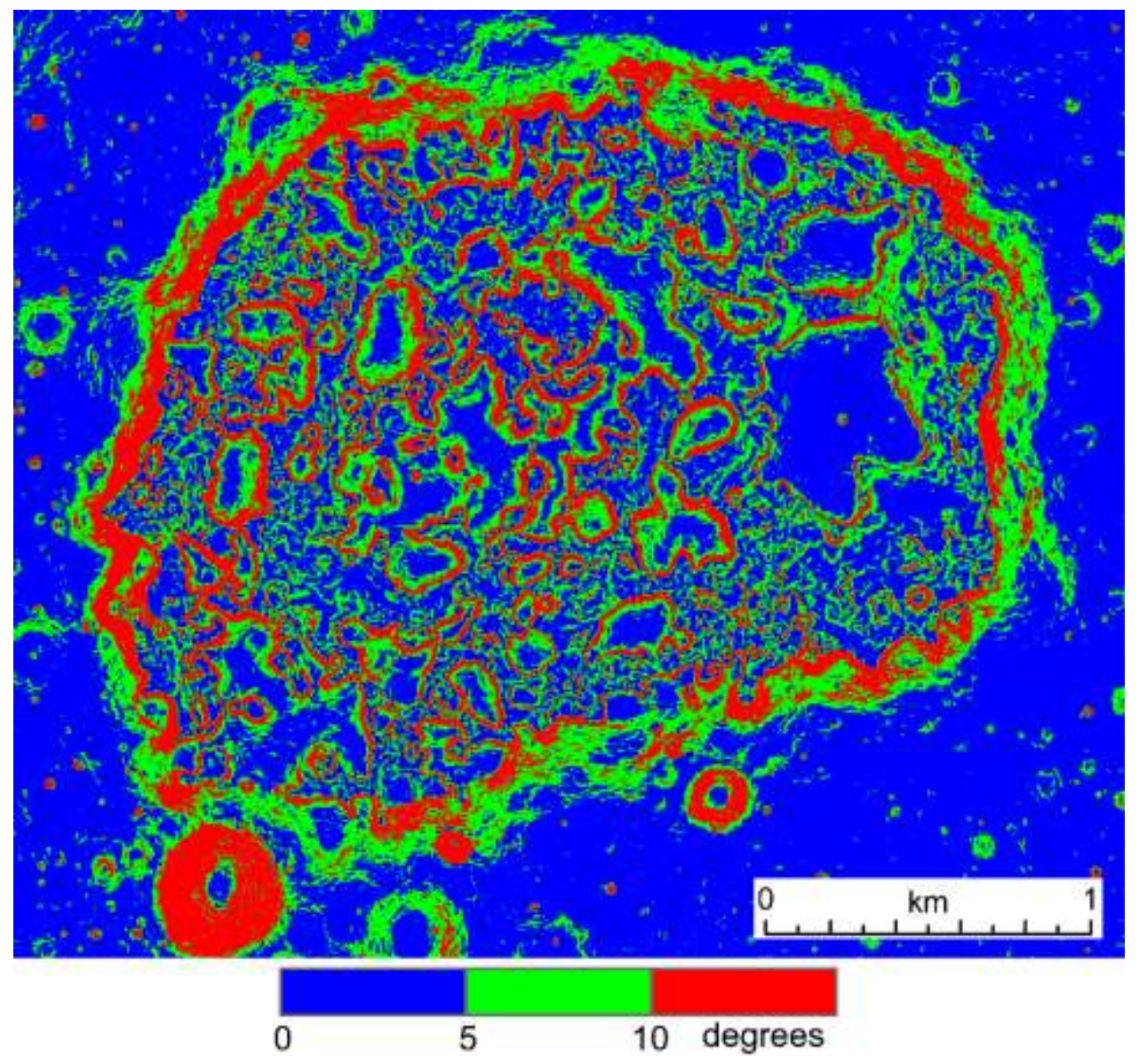

Fig. DR2. Slope map of the Ina interior, derived from LROC NAC DTM, $2 \mathrm{~m} /$ pixel, baseline is $6 \mathrm{~m}$. 

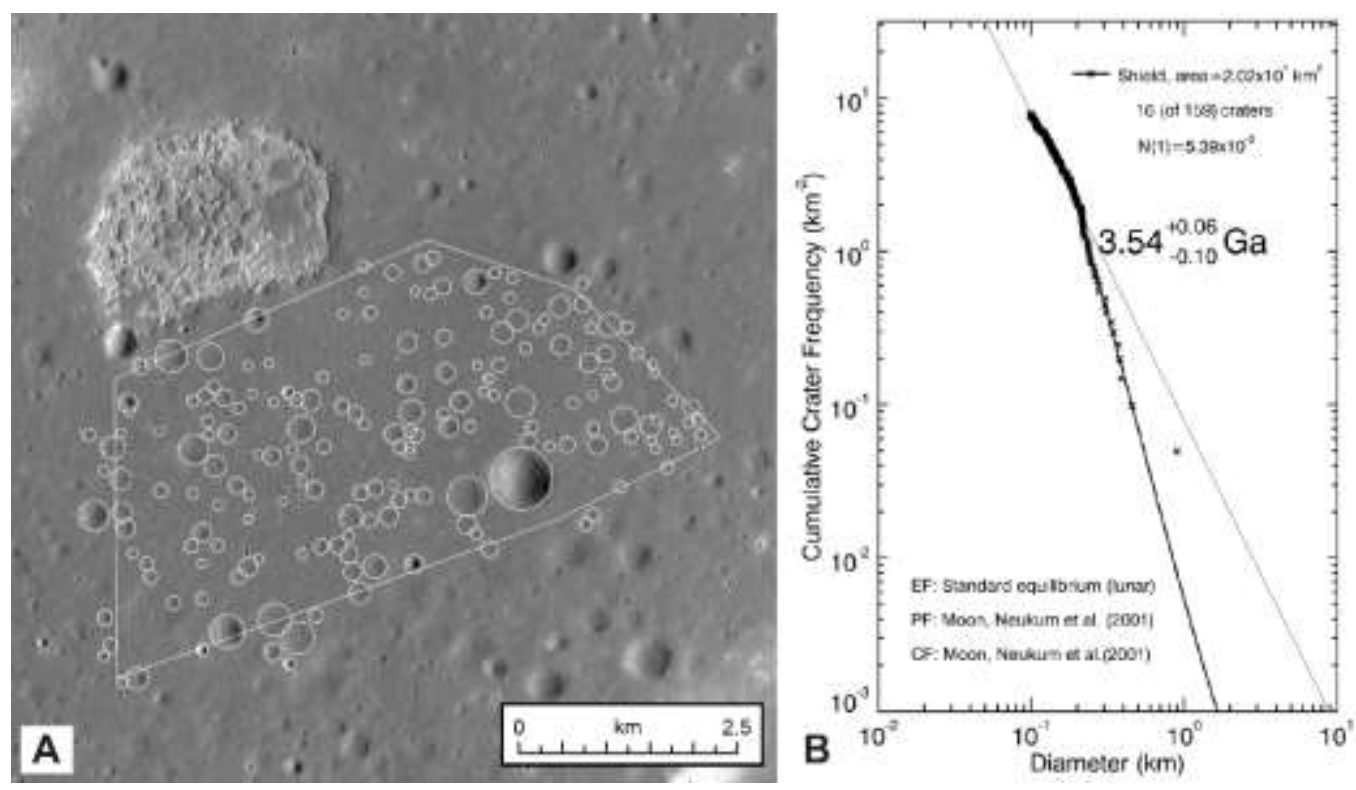

Fig. DR3. Impact crater size-frequency distribution analysis of the flanks of the shield volcano below the Ina pit crater. (A) Impact craters $\geq 100 \mathrm{~m}$ in diameter identified on the flanks of the shield volcano, based on LROC NAC frame M1138873574, $1.2 \mathrm{~m} / \mathrm{pixel}, 66^{\circ}$ incidence angle. (B) Cumulative size frequency distribution of crater counts; shows equilibrium population at $\mathrm{D} \leq \sim 220 \mathrm{~m}$. The gray curve is the lunar equilibrium curve. Production function fit for craters $\geq 250 \mathrm{~m}$ in diameter gives an absolute model age of $3.54(+0.06 /-0.10)$ Ga. (Neukum et al., 2001). 

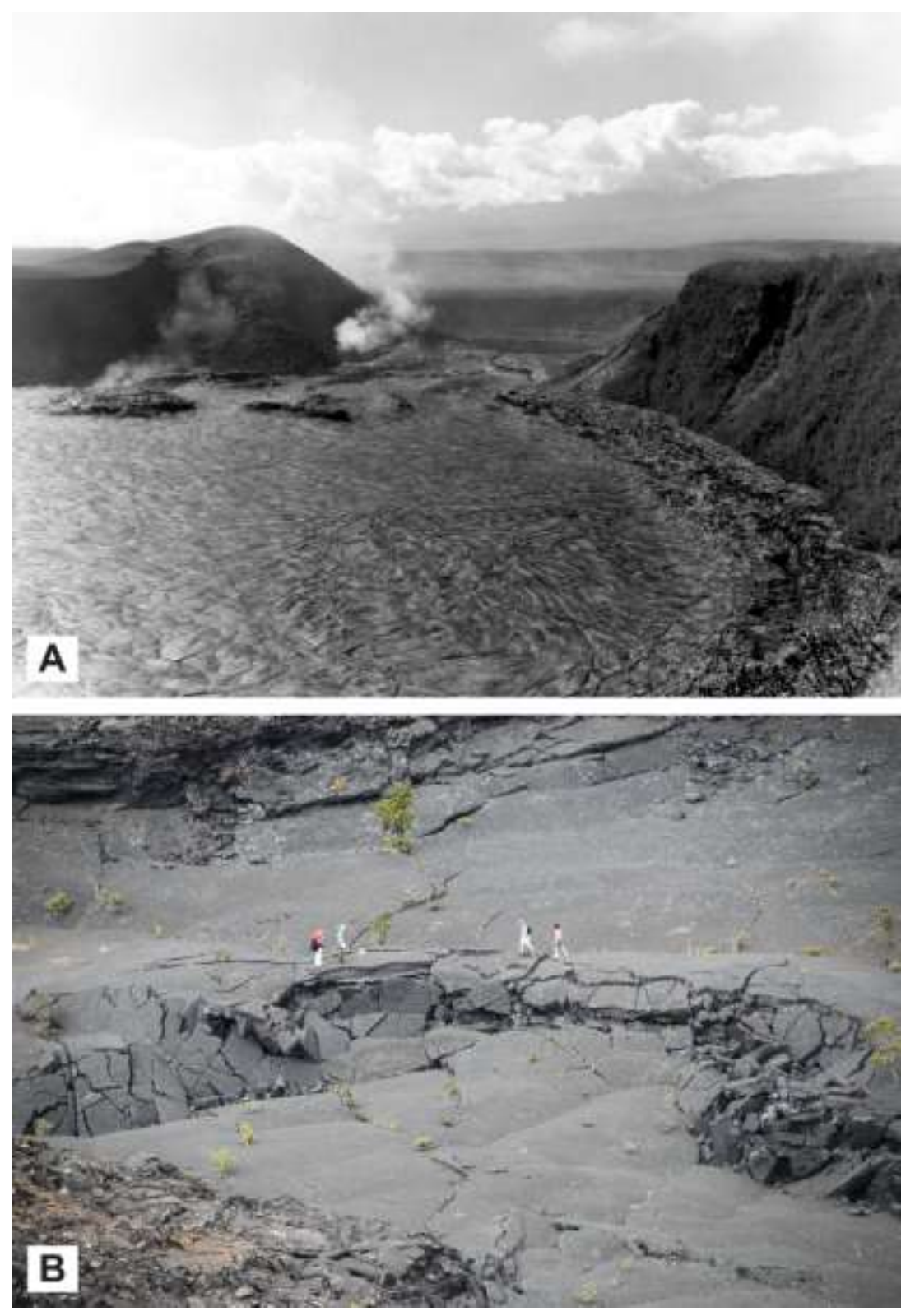

Fig. DR4. Shield volcano summit crater, Kïlauea Iki, Hawai'i. (A) 1959 eruption of Kīlauea Volcano, third phase of activity in Kīlauea Iki Crater. Note the chilled margin and inner scarp with tilted lava plates (right) and the chilled and blistered lava crust. USGS photo. (B) The floor of Killauea Iki. Note the draped plate at the edge of pre-eruption topography (top), the chilled marginal terrace, and the pressure ridge (center with hikers on top) formed by deformation of the subsiding rigid crustal layer on top of the lava lake. Note evidence for abundant void space associated with these deformed plates. U. S. National Park Service photo. 


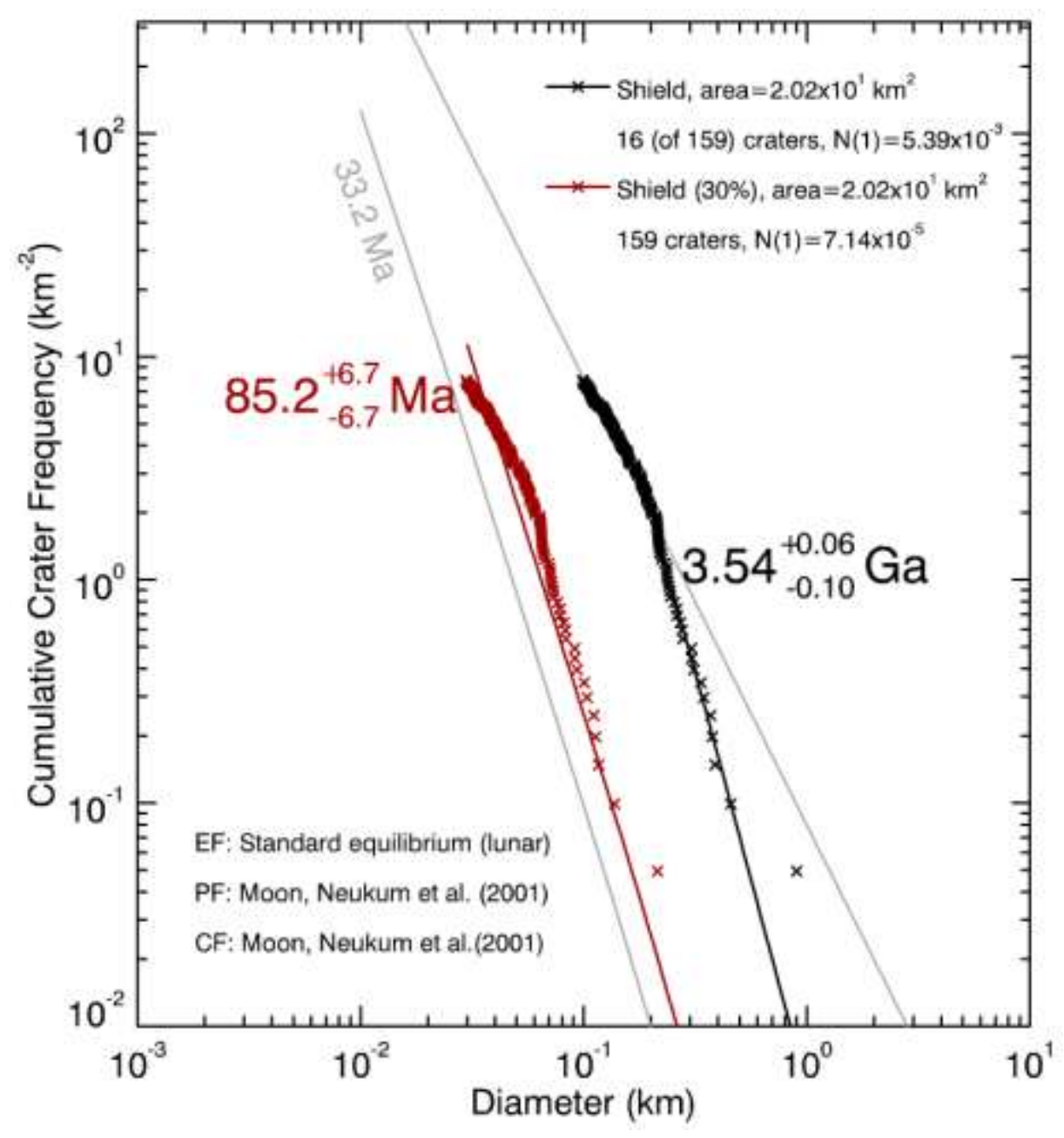

Fig. DR5. The effects of cratering a highly porous target (magmatic foam of the mounds) on the crater retention age. The original crater size frequency distribution of the shield volcano is plotted as black crosses. All the craters counted on the shield are scaled with a diameter decrease by a factor of 3 (plotted as red crosses), which yields a model age of $<100 \mathrm{Ma}$. The gray line in the right is the lunar equilibrium curve, and the left gray line is the isochron for the 33.2 Ma age reported by Braden et al. (2014). The factor of 3 reduction of crater diameters was derived in the following manner: (1) cratering efficiency (excavated mass/projectile mass) on highly porous targets is reduced to $\sim 1 \%$ compared with cratering on low-porosity materials (Schultz et al., 2002; Housen and Holsapple, 2003; Poelchau et al., 2013), (2) cratering efficiency (or excavated mass) is proportional to the density of the target materials times the cube of the crater diameter, (3) the density of $\sim 75 \%$ porosity target is $\sim(1-0.75) /(1-0.12)=0.28$ of typical lunar crust $(\sim 12 \%$ porosity), (4) $\sim 1 \%$ cratering efficiency corresponds to $\sim(0.01 / 0.28)^{1 / 3}=0.33$ scaling of crater diameter. 


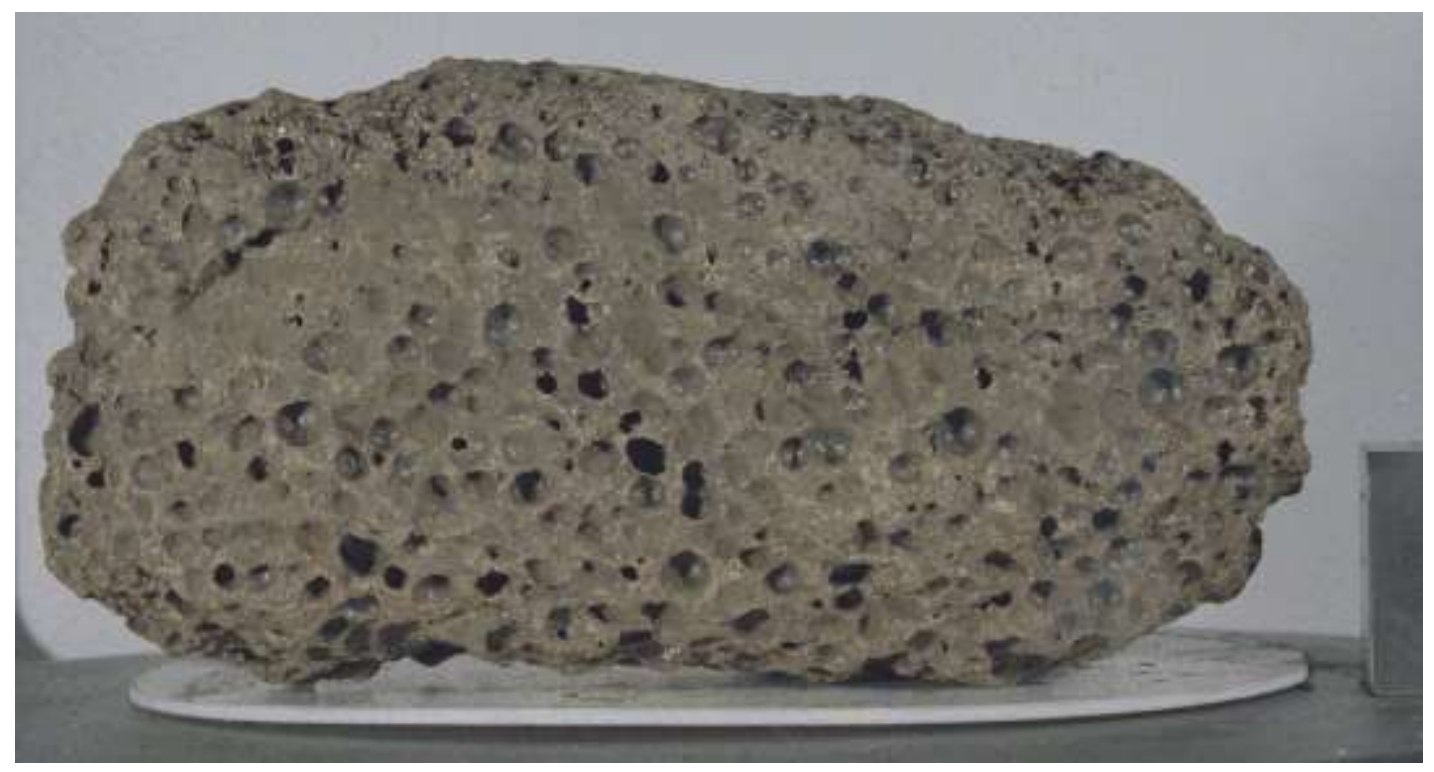

Figure DR6. Vesicular basalt 15016 collected by Astronaut David R. Scott on the Plains of Hadley during the Apollo 15 exploration of the Hadley/Apennine region. This highly vesicular basalt is $\sim 3.29$ billion years old (Evensen et al., 1973), and shows that extruded lunar basalts can retain significant volatiles in the form of bubbles during their emplacement on the surface. NASA photo.

\section{References}

Braden, S.E., Stopar, J.D., Robinson, M.S., Lawrence, S.J., van der Bogert, C.H., and Hiesinger, H., 2014, Evidence for basaltic volcanism on the Moon within the past 100 million years: Nature Geoscience, v. 7, p. 787-791, doi:10.1038/ngeo2252.

Evensen, N. M., Murthy, V. R. and Coscio, M. R., 1973, Rb-Sr ages of some mare basalts and the isotopic and trace element systematics in lunar fines. Proceedings of the Lunar Science Conference, v. 4, p. 1707-1724. 
Housen, K. R., and Holsapple, K. A., 2003, Impact cratering on porous asteroids: Icarus, v. 163, p. 102-119, doi:10/1016/S0019-1035(03)00024-1.

Neukum, G., Ivanov, B. A., and Hartmann, W. K., 2001, Cratering records in the inner solar system in relation to the lunar reference system: Space Science Reviews, v. 96, no. 1-4, p. 55-86, doi:10.1023/A:1011989004263.

Poelchau, M. H., Kenkmann, T., Thoma, K., Hoerth, T., Dufresne, A., and Schäfer, F., 2013, The MEMIN research unit: Scaling impact cratering experiments in porous sandstones: Meteoritics \& Planetary Science, v. 48, p. 8-22, doi:10.1111/maps.12016.

Schultz, P.H., Anderson, J.L.B., and Heineck, J.T., 2002, Impact crater size and evolution: Expectations for Deep Impact: Abstract 1875 presented at the 33rd Lunar and Planetary Science Conference, Houston, Texas, March 11-15, 2002. 